Thorax, 1980, 35, 859-864

\title{
Maximum volumes in excised human lungs: effects of age, emphysema, and formalin inflation
}

\author{
N BEREND, C SKOOG, L WASZKIEWICZ, AND W M THURLBECK
}

From the Department of Pathology, Health Sciences Centre, Winnipeg, Manitoba, Canada

ABSTRACT The volume of air at a transpulmonary pressure (PL) of $25 \mathrm{cmH}_{2} \mathrm{O}$ was measured in 28 emphysema-free and 39 emphysematous excised adult human lungs and in the lungs of 53 infants and children. In the adult emphysema-free lungs, this volume $\left(V_{25}\right)$ was significantly correlated with body length in males but, corrected for body length, not significantly correlated with age in either males or females. $V_{25}$ was on the average 20 per cent larger than predicted TLC in non-emphysematous lungs in vivo. The lungs were also inflated and fixed with formalin at a constant PL of $25 \mathrm{~cm}$ $\mathrm{H}_{2} \mathrm{O}$ and their volume measured $\left(\mathrm{VL}_{\mathrm{L}}\right)$. Marked and variable underinflation compared to $\mathrm{V}_{25}$ occurred in the adult lungs and $V_{L}$ minus lung weight averaged $75 \%$ of $V_{25}$ and $91 \%$ of predicted TLC. In infants and children, the ratio of $V_{L}$ minus lung weight to $V_{25}$ averaged 1.08 with a range of 0.58 to $1 \cdot 84$. The larger the lungs, the smaller the ratio, suggesting that fixation played a role in producing the small VL. In the emphysematous lungs, a significant correlation between the degree of emphysema and $V_{25}$ was found. However, a statistically significant increase in $V_{25}$ only occurred when the emphysema grade was greater than 5 .

Many studies have demonstrated a relationship between total lung capacity (TLC) and height, age and height, or height and weight in normal

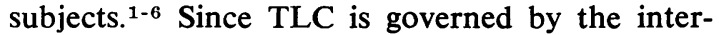
action of lung elastic properties, chest wall mechanics, and inspiratory muscle strength, it is of interest to document maximum lung volumes in excised lungs in which only lung elastic properties are a factor.

In patients with emphysema, TLC has been shown to be increased in some studies, ${ }^{7-9}$ but not in others, ${ }^{10-14}$ and there is uncertainty as to what degree of emphysema is necessary to produce such a change.

In morphometric studies of lung structure, it is common practice to inflate the lungs with a liquid fixative at a constant transpulmonary pressure $\left(\mathrm{PL}_{\mathrm{L}}\right)$ of $25 \mathrm{cmH}_{2} \mathrm{O}(2.5 \mathrm{kPa}){ }^{15-17}$ It has been shown that the lung volume attained by this method correlates with predicted TLC in life $\mathrm{e}^{1617}$ but that, in individual lungs, marked under and overinflation occurs.

In this study, we measured the volume of air in excised lungs distended at a $P_{L}$ of $25 \mathrm{~cm}$ $\mathrm{H}_{2} \mathrm{O}\left(\mathrm{V}_{25}\right)$ and the volume of the lungs fixed

Address for reprint requests: Dr N Berend, Department of Medicine, National Jewish Hospital, 3800 East Colfax Avenue, Denver, Colorado 80206, USA. in formalin at a constant $\mathrm{PL}$ of $25 \mathrm{cmH}_{2} \mathrm{O}(\mathrm{VL})$ of 28 non-emphysematous and 39 emphysematous excised human lungs in order to define: (1) the relationship of $V_{25}$ to age and height in nonemphysematous lungs, (2) the relationship of $V_{25}$ to the degree of emphysema, and (3) the relationship of $V_{L}$ to $V_{25}$.

\section{Methods}

Sixty-seven lungs (eight right, 59 left, 23 female, 44 male) were obtained at necropsy from subjects who died out of hospital from non-respiratory causes. Lungs with acute or chronic lung disease other than chronic bronchitis or emphysema were excluded. The pulmonary vasculature was ligated, the lungs weighed, the main bronchi cannulated, and the lungs tested for leaks. When small leaks were present, these were repaired by ligature or Krazy Glue ${ }^{R}$ (Krazy Glue Inc, Chicago, Illinois). The lungs were degassed and placed on a moist tray inside a volume displacement plethysmograph and inflated to a $\mathrm{PL}$ of $30 \mathrm{cmH}_{2} \mathrm{O}(3 \mathrm{kPa}), \mathrm{PL}_{\mathrm{L}}$ being measured with a Validyne DP15 pressure transducer. Volume change was measured with a Krogh spirometer. After the third inflation, the volume was measured first at a $\mathrm{PL}$ of $30 \mathrm{cmH}_{2} \mathrm{O}\left(\mathrm{V}_{30}\right)$ and then 
at a $\mathrm{PL}$ of $25 \mathrm{cmH}_{2} \mathrm{O}$ to make sure that the lungs were on the flat part of the expiratory pressure-volume curve. The manoeuvre was then repeated to check for reproducibility. In a separate experiment, three lungs were inflated to a $\mathrm{PL}$ of $20 \mathrm{cmH}_{2} \mathrm{O}(2 \mathrm{kPa})$ and then to a $\mathrm{PL}$ of $30 \mathrm{cmH}_{2} \mathrm{O}$ in order to study the effects of varying the maximum inspiratory $P_{L}$ on lung volume. The average increase in lung volume at the high pressure was only $3 \%$. Increasing the PL would, therefore, not lead to appreciably higher lung volumes and would also be impracticable as the incidence of leaks and interstitial emphysema increases substantially. $\mathrm{V}_{25}$ of the lungs was calculated by assuming that the left lung contributed $47 \%$ and the right lung $53 \%$ of TLC. ${ }^{18}$

The lungs were removed from the plethysmograph and inflated with $10 \%$ buffered formalin at a constant $\mathrm{PL}$ of $25 \mathrm{cmH}_{2} \mathrm{O}$ using a modification of the apparatus described by Heard. ${ }^{15}$ The lungs were observed when first inflated with formalin from a $\mathrm{PL}_{\mathrm{L}}$ of zero and apparent complete inflation occurred within a few minutes in all cases. Constant inflating presure of $25 \mathrm{cmH}_{2} \mathrm{O}$ was then maintained for two to three days. The bronchus was clamped and

Table 1 Sex, age, and lung volumes of 28 emphysema-free lungs

\begin{tabular}{|c|c|c|c|c|}
\hline Lung & Sex & Age $(y r)$ & $\begin{array}{l}\text { Ratio of } V_{25} \text { to } \\
\text { predicted TLC } \\
\left(\text { Knudson et al }{ }^{1}\right)\end{array}$ & $\begin{array}{l}\text { Ratio of } V_{25} \text { to } \\
\text { predicted TLC } \\
\text { (Goldman and Becklake }{ }^{2} \text { ) }\end{array}$ \\
\hline 1 & $\mathbf{F}$ & 47 & $1 \cdot 17$ & 1.08 \\
\hline 2 & $\mathbf{M}$ & 65 & $1 \cdot 18$ & $1 \cdot 20$ \\
\hline 3 & $\mathbf{M}$ & 22 & $1 \cdot 16$ & $1 \cdot 11$ \\
\hline 4 & $\mathbf{M}$ & 39 & $1 \cdot 17$ & $1 \cdot 15$ \\
\hline 5 & $\mathbf{M}$ & 35 & 1.08 & 1.01 \\
\hline 6 & M & 56 & 1.01 & 0.99 \\
\hline 7 & $\mathbf{M}$ & 22 & 1.08 & 1.02 \\
\hline 8 & $\mathbf{F}$ & 77 & 1.09 & 1.05 \\
\hline 9 & M & 44 & 0.99 & 0.99 \\
\hline 10 & $\mathbf{F}$ & 74 & 1.41 & $1 \cdot 37$ \\
\hline 11 & $\mathbf{F}$ & 76 & 0.95 & 0.91 \\
\hline 12 & M & 14 & 0.96 & 0.84 \\
\hline 13 & M & 55 & $1 \cdot 31$ & $1 \cdot 32$ \\
\hline 14 & M & 48 & 0.91 & 0.87 \\
\hline 15 & $\mathbf{M}$ & 16 & $1 \cdot 19$ & 1.05 \\
\hline 16 & $\mathbf{M}$ & 54 & $1 \cdot 26$ & $1 \cdot 26$ \\
\hline 17 & $\mathbf{M}$ & 55 & $1 \cdot 38$ & 1.37 \\
\hline 18 & $\mathbf{M}$ & 48 & $1 \cdot 20$ & $1 \cdot 16$ \\
\hline 19 & $\mathbf{F}$ & 52 & 1.44 & 1.33 \\
\hline 20 & $\mathbf{F}$ & 64 & 1.43 & 1.35 \\
\hline 21 & $\mathbf{M}$ & 17 & $1 \cdot 18$ & 1.03 \\
\hline 22 & $\mathbf{M}$ & 25 & $1 \cdot 11$ & 1.03 \\
\hline 23 & $\mathbf{M}$ & 41 & $1 \cdot 51$ & $1 \cdot 37$ \\
\hline 24 & $\mathbf{F}$ & 27 & 1.04 & 0.91 \\
\hline 25 & $\mathbf{F}$ & 86 & $1 \cdot 24$ & 1.23 \\
\hline 26 & $\mathbf{M}$ & 71 & 1.02 & 1.04 \\
\hline 27 & $\mathbf{F}$ & 58 & 1.64 & 1.57 \\
\hline \multirow[t]{2}{*}{28} & $\mathbf{F}$ & 63 & 1.09 & $1 \cdot 02$ \\
\hline & & $\begin{array}{l}\text { Mean } \\
\pm \text { SE } \pm\end{array}$ & $\begin{array}{l}1.20 \\
0.03\end{array}$ & $\begin{array}{l}1.14 \\
0.04\end{array}$ \\
\hline
\end{tabular}

the lung volume measured by water displace- $\frac{C}{\sigma}$ ment. Total lung volume $\left(V_{L}\right)$ was estimated by $\frac{\bar{\sigma}}{}$ assuming the same proportions for left and right $\Phi$ lungs as stated above. The lungs were sliced in a parasagittal plane and paper mounted whole lung os sections produced from midsagittal slice. These $\vec{\circ}$ were used to score the degree of emphysema on $\overrightarrow{\vec{\omega}}$ an arbitrary scale of $0-100 .{ }^{19}$ An adjacent to ${ }^{\omega}$ midsagittal slice from each lung was impregnated $\vec{x}$ with barium sulphate and examined under the $\underset{\omega}{*}$

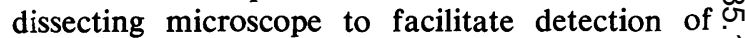
minor degrees of emphysema.

In a separate study, the disease-free lungs from of 53 neonates, infants, and children were similarly $\mathbb{C}$ inflated with air to a $\mathrm{PL}_{\mathrm{L}}$ of $25 \mathrm{cmH}_{2} \mathrm{O}$ and sub- $\frac{\text { ? }}{3}$ sequently formalin fixed at the same pressure. $\overrightarrow{ }$ The ratio of (VL minus lung weight) $/ V_{25}$ was $Z$ calculated for all the lungs. Lung weight was subtracted from $V_{L}$ since $V_{L}$ includes the 3 volume of lung tissue and this was assumed to $\stackrel{\Phi}{~}$ have a density of $1 \cdot 0$.

The relationship of $V_{25}$ to age, postmortem body length $(\mathrm{cm})$, and emphysema grade was determined using regression analysis. Predicted TLC during life for height and age were calculated using the data of Knudson et al ${ }^{1}$ (TLC $\overline{0}$ related to height only) and Goldman and Becklake $^{2}$ (TLC related to age and height).

\section{Results}

Twenty-eight lungs including those of 10 females were found to be free from emphysema. The ratio $\pm S D$ of $V_{25}$ to $V_{30}$ in these lungs was 을 $0.997 \pm 0.005$. The age, sex, observed $V_{25}$, and $\stackrel{x}{x}$ ratios of $\mathrm{V}_{25}$ to predicted TLC in life using the data of Knudson $e t l^{1}$ and Goldman and Becklake $^{2}$ are shown in the table 2. It can be seen 0 that $V_{25}$ in excised lungs was nearly always higher than TLC expected in life and averaged $\mathrm{O}$ $20 \%$ greater than predicted by Knudson et $a l^{1} D$ and $14 \%$ greater than predicted by Goldman and Becklake. ${ }^{2}$ For male lungs, a significant correlation with height was found $\left(\mathrm{V}_{25}=0.089^{\mathrm{G}}\right.$ height $-8.05, \mathrm{r}=0.57, \mathrm{p}<0.05$ ) but not for females $(r=0 \cdot 47)$. However, there was a trend for the females and the lack of significance mayo have been the result of the narrow height rangee $(156-168 \mathrm{~cm})$ compared with the males $(160-187 \AA$ $\mathrm{cm})$ and the small number of cases. The? regression line for males is compared with that 0 obtained by Knudson et $a^{1}$ in fig 1 . There was $\stackrel{0}{\mathbb{D}}$ no difference in slope but a significant difference in elevation $(p<0.025)$. Since the volumes in $\stackrel{2}{2}$ this study were measured at ATP and the volumes in vivo are corrected to BTPS, the 


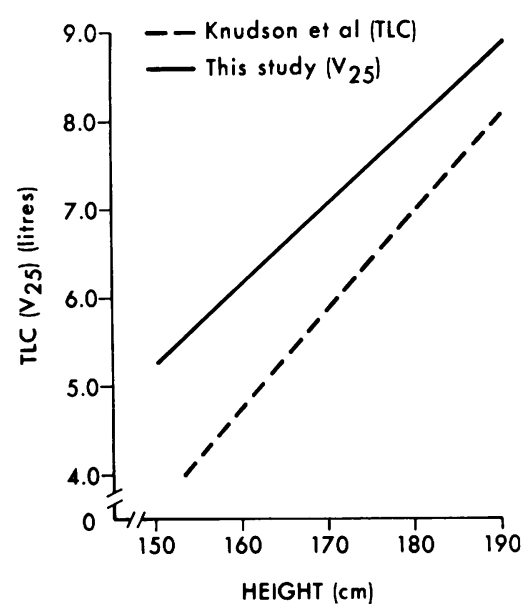

Fig 1 Relationship between the regression lines of TLC versus height in vivo and $V_{25}$ versus height in excised lungs. The slopes are not significantly different, but the elevation of $V_{25}$ versus height is significantly higher.

difference in elevation is even greater. There was no significant correlation of $\mathrm{V}_{25}$ with age independent of height in males or females (age versus $\mathrm{V}_{25} /$ height $^{3}, \mathrm{r}=0.32, \mathrm{r}=0.09$ for males and females, respectively). For the latter calculation, the data of the three males under the age of 20 years were excluded since height increases up to adulthood and then declines with age. There was also no significant correlation between ( $V_{L}$ minus lung weight)/height ${ }^{3}$ and age $(r=0.07, r=0.25$, for males and females, respectively).

The ratio of $\mathrm{VL}_{L}$ minus lung weight to $\mathrm{V}_{25}$ in the normal lungs was $0.75 \pm 0.02$ with no significant difference between males and females. There was also no correlation between the lung size $\left(V_{25}\right)$ and this ratio $(r=-0 \cdot 11)$ or age and this ratio $(r=0.06)$. The range of ratios was 0.48 to 0.94 . The ratio of $V_{L}$ minus lung weight to predicted TLC was $0.91 \pm 0.03$ and was not related to age $(r=0.28)$. The $V_{L}$ minus lung weight was significantly lower than predicted TLC ( $p<0 \cdot 01$, paired Student's $t$ test). Therefore, the correction factor which would need to be applied to any linear measurement in these lungs to correct back to $V_{25}$ ranged from $1 \cdot 28$ to $1 \cdot 02$ (mean $1 \cdot 10$ ), being given by $\left(V_{25} / V_{L}\right.$ minus lung weight). ${ }^{1 / 3}$ However, to correct back to TLC in life, the mean factor is only 1.03 (predicted $\mathrm{TLC} / \mathrm{VL}_{\mathrm{L}}$ minus lung weight). $1 / 3$

In the children's lungs, $V_{25}$ ranged from $4 \cdot 4$ to $1905 \mathrm{ml}$ and the $\mathrm{VL}_{L}$ minus lung weight $/ \mathrm{V}_{25}$ ratios ranged from $0 \cdot 58$ to $1 \cdot 84$ (mean $\pm \mathrm{SD}=$ $1 \cdot 08 \pm 0 \cdot 38$ ). However, a significant relationship between $V_{25}$ and this ratio was found $V_{L}$ minus lung weight $/ V_{25}$ ratios ranged from 0.58 to 1.84 (mean $\pm \mathrm{SD}=1 \cdot 08 \pm 0 \cdot 38$ ). However, a significant relationship between $V_{25}$ and this ratio was found ( $V_{L}$ minus lung weight $/ V_{25}=1 \cdot 14$ $\left.0.00026 \mathrm{~V}_{25}, \mathrm{r}=-0.41, \mathrm{p}<0.01\right)$.

In 39 lungs (age range $37-77 \mathrm{yr}$ ), varying degrees of emphysema were noted ranged from trace to grade 60 . The ratio of $V_{25}$ to $V_{30}$ in the emphysematous lungs was $0.999 \pm 0.002$. A significant relationship between the ratio of $V_{25}$ to predicted TLC during life (Knudson et $a l^{1}$ ) and the emphysema grade was found $\left(\mathrm{V}_{25}\right)$ predicted $\mathrm{TLC}=0.0075$ emphysema grade \pm $1 \cdot 23, \mathrm{r}=0.45, \mathrm{p}<0.01$ ). The emphysematous lungs were divided into three groups on the basis of the degree of emphysema. The ratios of $V_{25} /$ predicted TLC in the three groups can be seen in fig 2. Only in groups 2 and 3 was this ratio significantly higher than in the emphysema-free lungs. However, group 1 was not significantly different from groups 2 and 3 . A significant relationship between the ratio of $V_{25}$ /predicted $\mathrm{V}_{25}$ was also obtained $\left(\mathrm{V}_{25} /\right.$ predicted $\mathrm{V}_{25}=$ 0.0051 emphysema grade $+1.06, r=0.40$, $\mathrm{p}<0.05)$. The ratios of $\mathrm{V}_{25} /$ predicted $\mathrm{V}_{25}$ in the three groups (fig 3 ) yielded similar results to those in fig 2 with only groups 2 and 3 being significantly different from the emphysema-free lungs, but no difference between groups 1, 2, and 3.

The mean ratio \pm SD of $V_{L}$ minus lung weight $/ \mathrm{V}_{25}$ was $0.77 \pm 0.12$ with a range of

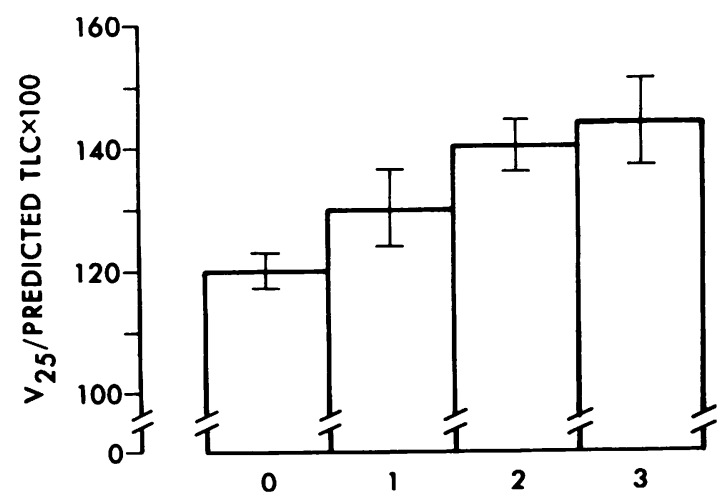

Fig $2 V_{25}$ expressed as a percentage of predicted TLC in vivo in the four groups of lungs. Groups 2 and 3 are significantly different from group 0 but there is no significant difference between groups 1, 2, and 3. Group $0=28$ emphysema-free lungs, group $1=11$ lungs with emphysema grade $0-5$, group $2=20$ lungs with emphysema grade 5-20, group $3=$ eight lungs with emphysema $>20$. 


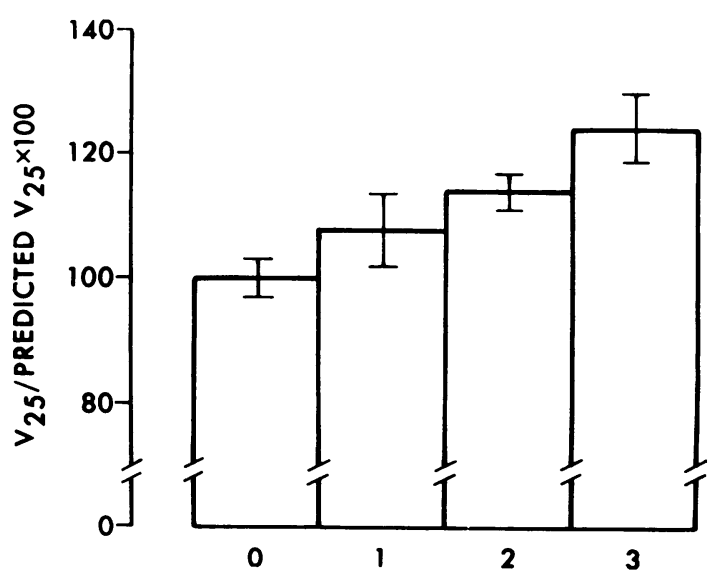

Fig $3 V_{25}$ expressed as a percentage of predicted $V_{25}$ in the four groups of lungs. (Predicted $V_{25}$ obtained from the relationship of $V_{25}$ to body length in emphysema-free lungs.) Groups 2 and 3 are significantly different from group 0 but there is no significant difference between groups 1, 2, and 3.

0.43 to 0.98 and this was very similar to the normal lungs. This ratio was not related to the emphysema grade $(r=0 \cdot 10)$.

The emphysema-free lungs were then combined with those showing minimal emphysemathat is, group 1 , in order to recalculate the age regression of $V_{25} /$ height $^{3}$. Again, the three male lungs under age 20 years were excluded. Now, the males demonstrated a significant relationship between age and $V_{25} /$ height $^{3}\left(V_{25}=0.0072\right.$ age $+1 \cdot 12, \mathrm{r}=0 \cdot 48, \mathrm{p}<0.05)$, but not the females.

\section{Discussion}

Many studies have shown that TLC in life in normal individuals is positively correlated with height. ${ }^{1-6}$ In some studies, TLC has also been shown to have a significant negative correlation with age independent of height. ${ }^{2} 4$ Since it has been well documented that lung elastic recoil decreases with age, ${ }^{120} 21$ it is thought that weaker inspiratory muscles in conjunction with a stiffer chest wall ${ }^{22}$ in older individuals either exactly counterbalances the loss of elastic recoil of the lungs or slightly overcompensates for it. In this study, $V_{25}$ was measured in excised lungs free of the effects of age-related changes in chest wall and respiratory muscle mechanics. It is, therefore, somewhat surprising that in the emphysemafree lungs, $V_{25}$ was only significantly related to height and not to age, although this is in keeping with the results of a previous study ${ }^{18}$ which showed no increase with age of VL corrected for height. There was a trend for the males to have a greater $V_{25}$ with increasing age but not for $\overline{\bar{s}}$ females, and this may be related to the observa- $\bar{\phi}$ tion that loss of elastic recoil with age is greater in males than in females. ${ }^{21}$ The $\mathrm{V}_{25}$ was shown ${ }^{\text {s }}$ to be close to maximum lung volume by the $\vec{\circ}$ demonstration that $V_{25}$ was on the plateaux of $\overrightarrow{-}$ both the inspiratory and expiratory pressure- $\omega$ volume curves. The $\mathrm{V}_{25}$ was consistently larger than predicted from data obtained in living subjects, averaging $20 \%$ increase compared with ${ }^{\top}$ the best prediction data. This suggests that the chest wall at all ages constrains the lungs andoo prevents them reaching their maximum volume or, alternatively, that some basic alteration in elastic properties of the lungs occurs after death. $\overrightarrow{-}$ In addition, despite loss of elastic recoil with age, the maximum lung volume remains fixed throughout life, governed by body size. Astrand 3 et $a l,{ }^{23}$ in a longitudinal study, demonstrated an® increase in TLC with age in a group of physically $\vec{\oplus}$ fit subjects. In the light of the present findings, this would be difficult to explain unless the chest wall became more compliant and respira-O tory muscles stronger with age.

There are a number of possible factors in thiso study which may affect these conclusions. Ifo height had been systematically underestimated by the measurement of postmortem body length, $\overrightarrow{\overrightarrow{0}}$ then the predicted values for TLC would be 3 falsely low. In addition, little was known about? the medical histories of these subjects. It is . possible that some of them may not have been in cluded in a series of normal, healthy volunteers? during life. On the other hand, it is also quitex possible, indeed likely, that the minimal or equivocal degreees of emphysema of the lungs in group 1 would not have led to their exclusion? from such a series. When they, with their inherent age bias and larger $V_{25}$, were combined with the emphysema-free lungs, a significant age $\rightarrow$ related change in $V_{25}$ resulted in males.

If lungs are distended with formalin, the bronchi tied and left overnight, they lose about $25 \%$ of lung volume. ${ }^{24}$ It is in order to overcomeo this shrinkage that a constant $P_{L}$ is used duringes the time of fixation. However, in the present study, despite application of constant pressure underinflation of varying degree occurred compared to $\mathrm{V}_{25}$. Because of this underinflation, the linear measurement of a structure in the fixed lung would need to be increased by an average of $10 \%$ but in some individual lungs, by up to? $30 \%$ to correct back to $V_{25}$, whereas much lowero factors correct back to TLC during life.

The question arises as to which is the "correct" 
lung volume for morphometric purposes. $V_{L}$ minus lung weight is close to predicted TLC in this series, averaging $91 \%$. (VL minus predicted ideal lung weight would be closer to TLC since many of the lungs were heavy.) In another study, ${ }^{18}$ we have shown that $V_{L}$ is, on the average, $8 \%$ greater than radiologically determined TLC and when allowance is made for volume of tissue, the results of the two studies are similar. It thus appears that fixation proceeds rapidly enough to make the lung stiffer so that $V_{L}$ never reaches $V_{25}$ and fortuitously, approaches TLC. However, since the relationship between $V_{25}$ and $V_{L}$ was not related in the adult lungs to sex, age, or lung size, it may be better to measure $V_{25}$ first so that the correction factors in individual lungs can be calculated.

It is interesting, however, that in the children's lungs which had a much greater range of lung volumes, a significant relationship between the degree of formalin inflation and $V_{25}$ was found. This suggests that since formalin inflation of the larger lungs takes longer, perhaps some fixation takes place during inflation thus limiting the maximum volume obtainable.

The lungs with emphysema demonstrated a $\mathrm{V}_{25}$ significantly greater than the normal lungs. However, when divided into groups according to the severity of emphysema, it became apparent that significant increases in $V_{25}$ occurred only when the emphysema grade was greater than 5 . However, since groups 1, 2, and 3 were not significantly different from each other, it may also be argued that the presence of emphysema is more important than the grade in determining increases in lung volume.

Underinflation with formalin of the emphysematous lungs occurred to an almost equal degree to that observed in the emphysemafree lungs. By inflating the lungs with air first and meticulously sealing all leaks when present, we can be certain that leakage was not a factor. However, emphysematous lungs tend to be leaky and when this occurs, VL may be expected to be even smaller. Therefore, once again, this suggests the need for preliminary air inflation. It should be noted that overinflation $\left(V_{L}\right.$ minus lung weight $/ \mathrm{V}_{25}$ ratio of $>1 \cdot 0$ ) was not observed in any lung in the present series.

This work was supported by MRC (Canada) Grant No. MA6179 and grants from the Royal Australasian College of Physicians and the Coppleson Postgraduate Medical Institute of the University of Sydney, New South Wales, Australia.

\section{References}

1 Knudson RJ, Clark DF, Kennedy TC, Knudson DE. Effect of aging alone on mechanical properties of the normal adult human lung. $J A p p l$ Physiol 1977; 43:1054-62.

2 Goldman HI, Becklake MR. Respiratory function tests. Normal values at median altitudes and the prediction of normal results. Am Rev Respir Dis 1959; 79:457-67.

3 Kaltreider NL, Fray WW, Van Zile Hyde H. The effect of age on the total pulmonary capacity and its subdivisions. Am Rev Tuberc 1938; 37: $662-89$.

4 Needham CD, Rogan MC, McDonald I. Normal standards for lung volumes, intrapulmonary gasmixing, and maximum breathing capacity. Thorax 1954; 9:313-25.

5 Grimby G, Söderholm B. Spirometric studies in normal subjects. III. Static lung volumes and maximum voluntary ventilation in adults with a note on physical fitness. Acta Med Scand 1963; 173:199-206.

6 Marshall $R$. The physical properties of the lungs in relation to the subdivisions of lung volume. Clin Sci 1957; 16:507-15.

7 Finucane KE, Colebatch HJH. Elastic behavior of the lung in patients with airway obstruction. J Appl Physiol 1969; 26:330-8.

8 Boushy SF, Aboumrad MH, North LB, Helgason AH. Lung recoil pressure, airway resistance and forced flows related to morphologic emphysema. Am Rev Respir Dis 1971; 104:551-61.

9 Pratt PC, Jutabha O, Klugh GA. Quantitative relationship between structural extent of centrilobular emphysema and post mortem volume and flow characteristics of lungs. Med Thorac 1965; 22:197-208.

10 Gelb AF, Gold WM, Wright RR, Bruch HR, Nadel JA. Physiologic diagnosis of subclinical emphysema. Am Rev Respir Dis 1973; 107:50-63.

11 Zamel N, Hogg J, Gelb A. Mechanisms of maximal expiratory flow limitation in clinically unsuspected emphysema and obstruction of the peripheral airways. Am Rev Respir Dis 1976; 113:337-45.

12 Watanabe S, Mitchell M, Renzetti AD. Correlation of structure and function in chronic pulmonary emphysema. Am Rev Respir Dis 1965; 92:221-7.

13 Thurlbeck WM, Henderson JA, Fraser RG, Bates DV. Chronic obstructive lung disease. A comparison between clinical, roentgenologic, functional and morphologic criteria in chronic bronchitis, emphysema, asthma and bronchiectasis. Medicine 1970; 49:81-145.

14 Jenkins DE, Greenberg SD, Boushy SF, Schweppe HI, O'Neal RM. Correlation of morphologic emphysema with pulmonary function parameters. Trans Assoc Am Physicians 1965; 78:218-30.

15 Heard BE. A pathological study of emphysema 
of the lungs with chronic bronchitis. Thorax 1958; 13:136-49.

16 Matsuba K, Thurlbeck WM. The number and dimensions of small airways in non-emphysematous lungs. Am Rev Respir Dis 1971; 104: 516-24.

17 Matsuba K, Thurlbeck WM. The number and dimensions of small airways in emphysematous lungs. Am J Pathol 1972; 67:265-75.

18 Thurlbeck WM. Post mortem lung volumes. Thorax 1980; in press.

19 Thurlbeck WM, Dunnill MS, Hartung WS, Heard BE, Heppleston AG, Ryder RC. A comparison of three methods of measuring emphysema. Hum Pathol 1970; 1:215-26.

20 Turner JM, Mead J, Wohl ME. Elasticity of human lungs in relation to age. J Appl Physiol
1968; 25:664-71.

21 Bode FR, Dosman J, Martin RR, Ghezzo H, Macklem PT. Age and sex differences in lung elasticity, and in closing capacity in non-smokers. $\triangle$ J Appl Physiol 1976; 41:129-35.

22 Mittman C, Edelman NH, Norris AH, Shock ${ }^{\text {cs }}$ NW. Relationship between chest wall and pul- $\vec{O}$ monary compliance and age. J Appl Physiol 1965; 20:1211-6.

23 Astrand I, Astrand PO, Hallbäck I, Kilbom A. Reduction in maximal oxygen uptake with age. $\times$ J Appl Physiol 1973; 35:649-54.

24 Thurlbeck WM. The incidence of pulmonaryemphysema: with observations on the relative. incidence and spatial distribution of various types $c$ of emphysema. Am Rev Respir Dis 1963; 87: 206-15. 